\title{
CONSOLIDATION OF NATURAL STONE WITH CALCIUM HYDROXIDE NANOSUSPENSION IN ETHANOL AND VERIFICATION OF SURFACE HARDENING RATE
}

\author{
KLÁRA KROFTOVÁ ${ }^{1}$, DAVID ŠKODA ${ }^{2}$, JIŘÍ WITZANY ${ }^{3} \&$ TOMÁS̆ ČEJKA ${ }^{3}$ \\ ${ }^{1}$ Department of Architecture, Faculty of Civil Engineering, Czech Republic \\ ${ }^{2}$ Centre of Polymer Systems, Tomas Bata University in Zlin, Czech Republic \\ ${ }^{3}$ Department of Building Structures, Faculty of Civil Engineering, Czech Republic
}

\begin{abstract}
The modern consolidating agents, used in the care of cultural heritage for the past 20 years, include dispersion and colloid systems of not only organic consolidants, but also mineral systems with particle sizes in nano-dimensions. Among these materials, calcium hydroxide nanodispersion plays an important role. The compatibility of the consolidant with the lime-based original building material, deep penetration due to the particle size, and no mobilisation of soluble salts are advantages attributed to alcoholic lime nanodispersions. The assessment of the consolidating efficiency of the tested products are based on performance of both the destructive and the non-destructive laboratory tests. The penetration depth, thermal and moisture expansion, material strength, abrasion, modulus of elasticity, vapor permeability, microstructure (porosity, pore distribution and interconnection) and density can be listed as monitored criteria. For historical material is also important to monitor the change of color or texture on visible surface of the material. The paper presents a partial result of the NAKI II DG16P02M005 research project dealing with the verification of potential use of selected lime nanosuspensions (newly prepared calcium hydroxide nanosuspensions in alcohols and market available lime-nanodispersion CaLoSiL $\left.{ }^{\circledR}\right)$ for the consolidation of historic lime based materials. The paper presents a comparative laboratory and experimental study on the effects of three different calcium hydroxide based agents on consolidating a porous limestone.
\end{abstract}

Keywords: stone, limestone, lime water, nanosuspension, CaLoSiL, consolidation, strengthening.

\section{INTRODUCTION}

The stone structures of the cultural heritage buildings show many different deterioration patters that are besides caused by their permanent exposure to the external environment, mainly the weather changes (temperature, sun exposure, wetness, etc.). The consolidation of those sanding, scaling and flaking materials is based on improvement of the mechanical properties, on strengthening of the subsurface and surface layers with the aim to return as close as possible to a state of its original properties. It mostly constitutes of restoration of the structure binder, filling the resulting cavities and cracks, increasing the adhesion of the surface layers to the substrate and removing the soils contained in the pores of the stone as much as possible [1].

The use of nanomaterials with a particle size of up to 150-300 (500) $\mathrm{nm}$ in the stone monument care, whose properties can be described as an intersection between molecular and mass properties, is the subject of scientific research of last 10 years approximately, mainly due to their positive physical and mechanical characteristics such as formation of stone-like compounds (in case of limestone the calcium carbonate chemical and mineralogical composition), possible deep penetration and high reactivity in the treated material [2], [3]. The possibility of stone consolidation by means of calcium hydroxide nanodispersion dispersed in an alcoholic environment was, for example, discussed in 2006 at the University of Firenze di Firenze in Italy. Laboratory tests carried out on limestone samples (Gallina and Alberese) showed an increase in surface cohesion and an increase in the $\mathrm{Ca} / \mathrm{Si}$ ratio (Gallina 
1.3:3.3; Alberese 8.93:18.3) without altering the color. The rate of water absorption also decreased after the application of nanodispersion (e.g. $5 \%$ for Alberese limestone, $1.7 \%$ after application) [4].

At present there are two commercially available nanosol products for conservation of calcium carbonate based materials, e.g. stone, as well as plaster and mortar. The commercial treatment products are CaLoSil (IBZ Salchemie, Germany) and Nanorestore (CSGI Consortium, University of Florence, Italy). There are many examples known for conservation by those named nanosuspensions of plaster and wall paintings [5], but only a few about consolidation of stone monuments [6], [7].

The paper presents partial results of the NAKI research project focused on possibilities of the stabilization, conservation and strengthening of historic stones by selected agents based on calcium hydroxide nanosuspensions (so called "nanolime"). It focuses on laboratory testing of newly developed nanosuspensions and their influence on material characteristics of limestone.

\section{MATERIALS AND METHODS}

Within the framework of the NAKI research project it's being carried out an extensive research dealing with the solution of the use of nanomaterials for conservation of historical materials (plaster, mortar and stone). The research is done in cooperation of the Faculty of Civil Engineering, Czech Technical University in Prague, and the Centre of Polymer Systems, Tomas Bata University in Zlín [8]-[10].

\subsection{Stone}

The laboratory tests were carried out on limestone samples, which is a calcium based material with open porosity and good absorbability (Fig. 1). Limestones was less frequently used in the construction of buildings in Czech Republic in the past centuries, but was widely used in Italy or Greece for example. In Czech Republic the use of limestone was usually due to the local quarry and the buildings were in a relatively small scale. The major area with limestone quarries in Bohemia is located in the surrounding of the town of Beroun (Bohemian Karst), but also in the north-west Bohemia (Czech Cretaceous Basin) or in Moravia in the area of Moravian Karst.

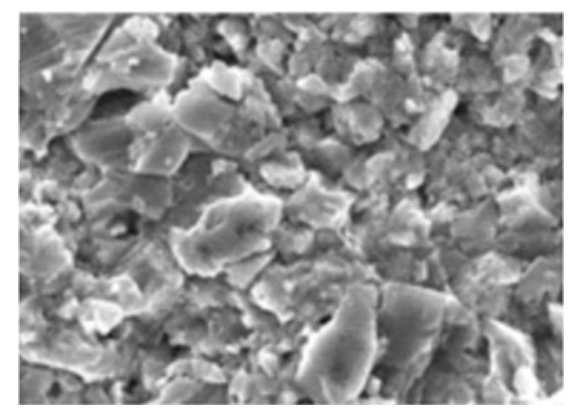

Figure 1: Microscopic image of limestone, Beroun Quarry. (Source: Neubergerová, 2015.)

For the laboratory tests were used the limestone from the Beroun quarry. The samples itself were of circular cross-section with a diameter of $5 \mathrm{~cm}$ and only one face of the sample 
Table 1: Physical characteristics of limestone samples.

\begin{tabular}{c|c|c}
\hline \multirow{2}{*}{ Stone } & \multicolumn{2}{|c}{ Physical characteristics } \\
\cline { 2 - 3 } & $\begin{array}{c}\text { Water absorption } \\
\% \mathrm{wt} .\end{array}$ & $\begin{array}{c}\text { Porosity } \\
\text { \% vol. }\end{array}$ \\
\hline Limestone & $1.31-2.25$ & $7.24-9.28$ \\
\hline
\end{tabular}

was treated with a certain volume of the tested nanosuspensions. Before the experiment, the stone specimens were conditioned in the laboratory environment at $25^{\circ} \mathrm{C}$ and humidity of $38 \%$.

Within the laboratory research we carried out the measurements of porosity in cooperation with the Institute of Rock Structure and Mechanics of the Academy of Sciences CR using the method of high-pressure mercury porosimetry on limestone samples. The measurement was performed on $5 \mathrm{~mm}$ sample fragments and performed on a set of Pascal $140+240$ fir thermo Electon-poroset (Table 1).

The assessment of efficiency of application we based on simple methods such as evaluation of the visual appearance - assessment of colour changes, the depths of penetration, the behaviour of the nanosuspensions in the course of application as well as the comparison of the samples porosity before and after application.

\subsection{Nanosuspensions}

In the framework of the research project, the original lime nanosuspensions were developed in cooperation with CPS in Zlín. Based on results of the previous research were prepared and tested 3 different lime nanosuspensions [9]:

- Ca4: $\mathrm{Ca}(\mathrm{OMe})_{2}$ dispersed in isopropyl alcohol was then added to distilled water; the reaction was stirred at room temperature for 3 hours; subsequently, the suspension was centrifuged and washed with distilled water and isopropyl alcohol; suspensions were prepared at a concentration of $5 \mathrm{~g} / \mathrm{l}$.

- Ca4O: the calcium oxide charge was dispersed in ethanol and distilled water was added; the mixture was left on a magnetic stirrer for 24 hours; the resulting suspension was made up to 1 liter by adding the reaction mixture; the $\mathrm{Ca}(\mathrm{OH})_{2}$ concentration is $5 \mathrm{~g} / \mathrm{l}$.

- CaMg1: the amounts of $\mathrm{Ca}, \mathrm{Mg}$ precursors and $\mathrm{NaOH}$ were dissolved in distilled water; subsequently, the $\mathrm{NaOH}$ solution was mixed with the precursor solution to form a white precipitate; the reaction was stirred at room temperature for 3 hours; the suspension was centrifuged and washed with distilled water and isopropyl alcohol; suspensions were prepared at a concentration of $5 \mathrm{~g} / \mathrm{l}$.

To determine the crystalline structure of the products was used the XRD powder analysis on a Rigaku MiniFlex 600 diffractometer and compared with the JCPDS card of $\mathrm{Ca}(\mathrm{OH})_{2}$ (JCPDS 01-076-0571) (Fig. 2).

\subsection{Application procedure}

Based on the previous laboratory research the application of consolidation means was done by a total volume of $30 \mathrm{ml}$. (Note: This volume doesn't correspond with a full volume needed for conservation of degraded historical material by calcium hydroxide nanosols, but is 


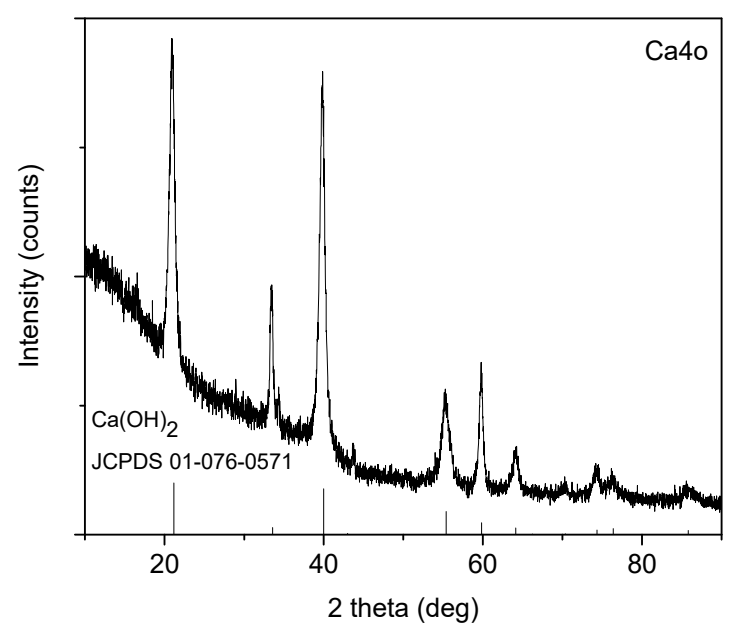

(a)

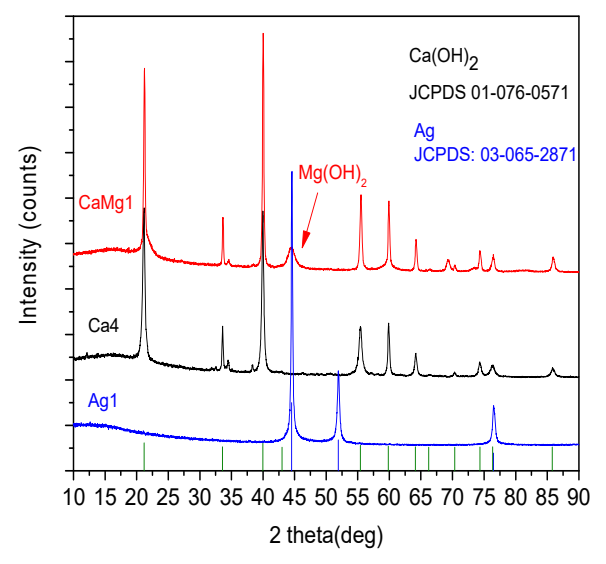

(b)

Figure 2: The XRD powder analysis of the products, Rigaku MiniFlex 600 diffractometer. (a) $\mathrm{Ca} 4 \mathrm{O}$; and (b) $\mathrm{Ca} 4$ (black); and $\mathrm{CaMg} 1$ (red).

sufficient to carry out the laboratory tests.) The nanosuspensions were applied to only one surface of the stone samples. The samples were placed in a measured amount of the tested nanosuspensions and covered with a foil to prevent the alcohol from evaporating too quickly. The penetration rate was continuously monitored and measured (Fig. 3(a)).

Consolidated test samples were left for 28 days of maturity, with continuous control and recording of color changes. The test specimens were not moistened or otherwise regulated during maturation, only exposed to natural conditions. The calcium hydroxide should be present in the treated samples after the evaporation of alcohol and its conversion to calcium carbonate takes place the same way as for the conventional lime material, i.e. by reaction with atmospheric carbon dioxide. 


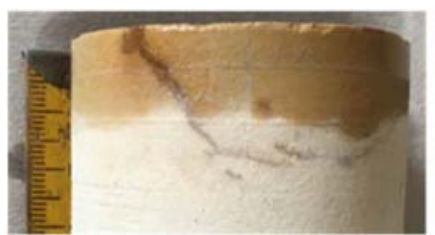

$\mathrm{Ca} 4$

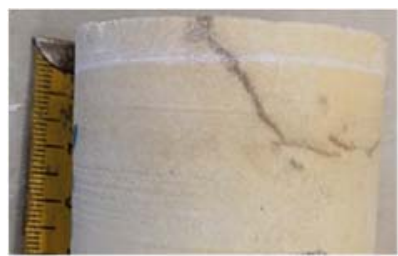

$\mathrm{Ca} 4$

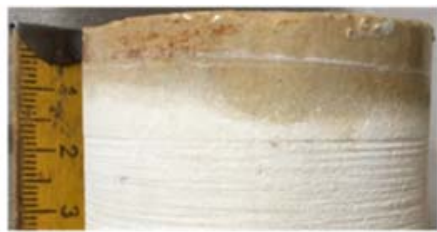

$\mathrm{Ca} 4 \mathrm{O}$

(a)

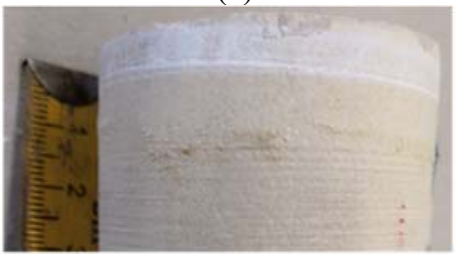

$\mathrm{Ca} 4 \mathrm{O}$

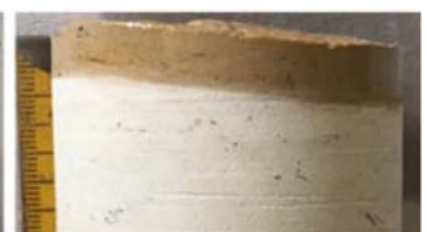

$\mathrm{CaMg} 1$

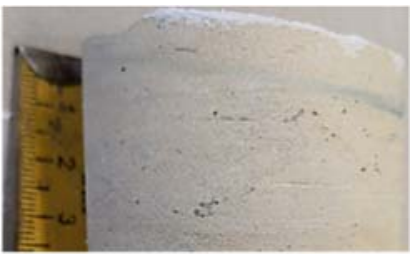

$\mathrm{CaMg} 1$

(b)

Figure 3: The limestone samples after application of nanosuspensions. (a) The penetration depth of nanosuspensions is clearly visible on the samples, it varies between $7 \mathrm{~mm}$ to $15 \mathrm{~mm}$; and (b) Visible accumulation of calcium hydroxide on the specimens surface.

One sample was left without the application of nanosuspensions to obtain a comparative characteristics for some measurements (e.g. cohesion of the surface layers or the porosimetry).

On the basis of mercury porosimetry results, the distribution and integral curves of the pore system of individual stone samples were constructed (Fig. 4), before and after the application of the consolidation agent. Samples for the determination of porosity after consolidation were taken from sites where the consolidation agent penetrated (about $10 \mathrm{~mm}$ from the edge of the element).

Table 2 shows the characteristic values of the limestone pore system before and after application of the consolidation agent, as determined by mercury porosimetry determined from the samples taken. Fig. 4 shows distribution and integral curves showing pore distribution from 0 to $10 \mathrm{~nm}$ radius up to 30,000 to $50,000 \mathrm{~nm}$ of selected samples.

In terms of efficiency and quality of consolidation of degraded stone surface, the cohesion of surface layers of material - i.e. before and after consolidation - is an important characteristic. Scanning electron microscopy indirectly provides information on the degree of deposition of consolidating substances (i.e. lime) in a porous degraded stone system. Verification of consolidation was done using scanning electron microscopy on SEM Nova NanoSEM (FEI) (5kV electron voltage, TLD detector).

Prior to the electron microscopy, the samples were embedded with an epoxy resin and then gilded. In the scanning electron microscopy of the individual test specimens we can trace the deposition rate of calcium carbonate in the porous sample system, created new bonds (bridges) between the individual grains of the filler, and assess the resulting consolidated material, i.e. crystalline state in particular. 


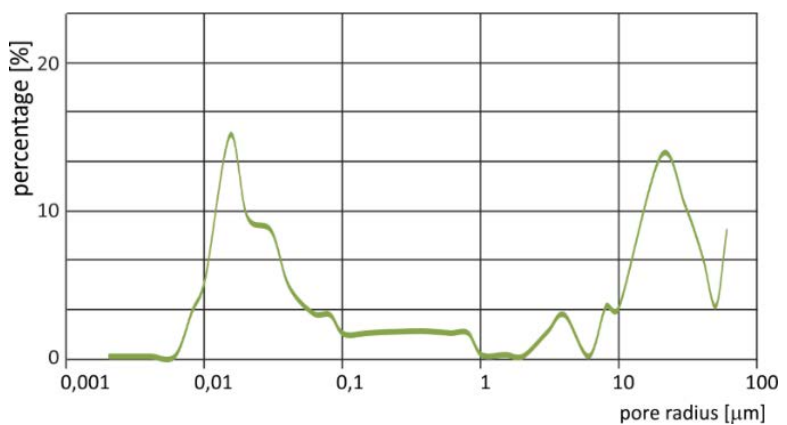

(a)

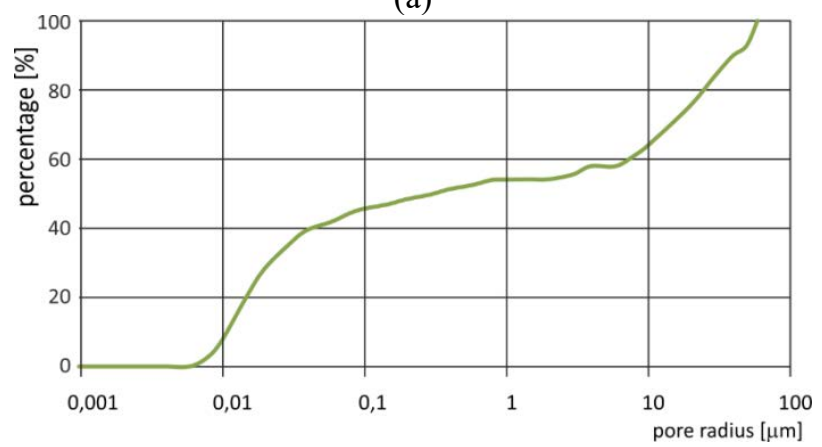

(b)

Figure 4: The pore system of limestone elements: treated with nanosuspension Ca4. (a) Distribution curves of pores; and (b) Integral curves of the pore system.

Table 2: Pore distribution in stone units: limestone specimen treated with nanosuspension Ca4. (Source: Witzany, 2018.)

\begin{tabular}{c|c|c|c|c|c|c|c|c|c}
\hline \multirow{2}{*}{$\begin{array}{c}\text { Material: } \\
\text { limestone }\end{array}$} & $\begin{array}{c}\text { Total } \\
\text { porosity } \\
\end{array}$ & \multicolumn{10}{|c}{ Pore radius (nm) } \\
\cline { 3 - 11 } & $0-10$ & $10-25$ & $25-150$ & $150-600$ & $\begin{array}{c}600- \\
2,000\end{array}$ & $\begin{array}{c}2,000- \\
7,500\end{array}$ & $\begin{array}{c}7,500- \\
30,000\end{array}$ & $\begin{array}{c}30,000- \\
50,000\end{array}$ \\
\hline before & 2.1 & 7.15 & 28.11 & 11.65 & 5.65 & 1.55 & 6.7 & 23.19 & 15.95 \\
\hline after & 1.4 & 7.35 & 28.94 & 12.69 & 5.42 & 1.42 & 6.7 & 22.83 & 14.65 \\
\hline
\end{tabular}

Note: Due to the small number of samples (1 sample before and 1 sample after the application), the stated values should be considered as informative.

\section{RESULTS AND DISCUSSION}

The recorded penetration depth of newly prepared nanosuspensions on the tested samples reaches max. $15 \mathrm{~mm}$ (in case of nanosuspension $\mathrm{Ca} 4$ ), $\mathrm{min} .7 \mathrm{~mm}$ (in case of nanosuspension $\mathrm{CaMg} 1)$. At the same time, hardening of the degraded material to a depth of 7-15 $\mathrm{mm}$ did not result in an impermeable surface film with high diffusion resistance.

The distribution and integral pores and total porosity curves shows the assessment of the influence of nanosuspensions on the pore system (perform the prevailing proportion of pores). The proportion of predominant pores of a certain size ranged from about $25-80 \%$ for individual types of evaluated materials in the total porosity [11]-[13]. Experimental research 
into the effect of nanosuspensions application on limestone porosity showed a change in total porosity due to used nanosuspension. For all used nanosols, the total porosity decreased between $1-9.5 \%$ of the total volume of the material and between $20 \%$ and $50 \%$ of the total pore volume. The total porosity of the limestone was $1 \%$ lower than in untreated materials.

The time needed for successful application of the tested amount of nanosuspension indicates a possible change of transport characteristics of the tested nanosuspensions within the stone specimen. The best results were obtained with the nanosuspension $\mathrm{Ca} 4$, the worst with nanosuspension $\mathrm{CaMg} 1$, where is significant accumulation of calcium hydroxide on the specimen's surface.

The scanning electron microscopy has proved some small deposition of calcium carbonate crystals in the specimen. The best calcium carbonate crystals have been recorded in the case of the application of nanosuspension CA4. Conversely, the smallest consolidation rate shows a sample of $\mathrm{CA} 4 \mathrm{O}$, where very small amounts of newly formed crystals corresponding to $\mathrm{CaCO} 3$ were identified.

The microscopic investigation showed the enrichment on the surface by the calcium hydroxide also.

\section{CONCLUSION}

Nanosuspensions of calcium hydroxide in alcohols represent the possibility of an almost anhydrous preservation of historical lime-based stone elements. The indisputable advantages of prepared lime nanodispersions in alcohol include their material compatibility with the original building material (i.e. limestone in this case), the small size of the lime particles (which should have a positive effect on the penetration depth) without mobilizing soluble salts in the material.

Laboratory tests have shown the possibilities and limits of developed lime nanosuspensions for structural consolidation of some calcium materials, i.e. limestones from Beroun region. The main advantages of lime-based nanosuspensions include the formation of calcium carbonate as a consolidation product, i.e. the formation of a binder of the same composition as in the original material, and thus meet the requirement of material compatibility with the substance being treated. Also, no by-products are produced during consolidation. Therefore, it can be assumed that the consolidation with lime-based nanosuspension does not develop the risk of secondary material damage.

The effect of consolidation was tested on limestone specimens. The specimens were treated by newly developed nanosuspensions of calcium hydroxide and the investigation showed that a satisfactory penetration depth of the consolidant and hence effective structural consolidation in this case is limited by the low porosity of the material, better results can be expected in the case of coarse porous materials.

The results of the limestone sample consolidation laboratory tests can be summarized as follows:

- Shallow penetration depth: the achieved penetration depth can be assessed as satisfactory for cases of shallow surface, not very developed, degradation of stone surfaces.

- The accumulation of calcium hydroxide on the specimen's surface after the treatment: the lowest ration was observed in case of nanosuspension $\mathrm{Ca} 4$, in the case of nanosuspension $\mathrm{CaMg} 1$ was observed white deposition on the treated surface.

- Due to the reduced porosity after the application of nanodispersions, it is possible to anticipate a decrease in water absorption and thus a reduction in the mobility of salts in the treated material. 
- The scanning electron microscopy proved only small depositions of calcium carbonate in specimens, the best results were obtained in the case of nanosuspension Ca4. (To achieve a higher degree of consolidation, a larger amount of consolidation agent is required.)

In order to improve the characteristics of nanosuspensions as well as results of experimental tests, further development of the tested nanosuspensions will carry on, e.g. by addition of acetone or ethanol as a dispersion medium to improve the distribution of nanosuspensions in the consolidated material [14].

Note 1: Certain dispersion of the measured values and thus the resulting characteristics is probably due to a certain deviation of the properties of the plaster at the individual supply points, the local moisture of the material, the unevenness of the plaster, the roughness, the rate of degradation of the surface and the manner of execution, in particular by pressing and the speed and the angle of tearing.

Note 2: The success of the firming process is influenced by a number of factors. Among the basic properties and parameters to be taken into consideration in the design of the reinforcement technology are: chemical and mineralogical composition of the reinforced material, strength of the material before consolidation, size and shape of the open pores, porosity, ion size, molecules or particles of the effective reinforcing agent in the stiffening the chemical composition and concentration of the active ingredient, the drying and hardening rate of the active substance in the reinforced substrate at the specific temperature and humidity conditions of the material and the ambient air. The knowledge of the above parameters is a good basis for the design of the reinforcement technology - type of strengthening agent, concentration of the active ingredient, method of application of the consolidant, number of repeated applications within one consolidation cycle, method of verification of the substrate after impregnation.

\section{ACKNOWLEDGEMENT}

This article was written as part of the NAKI DG16P02M055 research project "Development and Research of Materials, Methods and Technologies for the Restoration, Preservation and Strengthening of Historic Masonry Constructions and Surfaces and Systems of Preventive Conservation of Cultural Heritage Buildings Threatened by Anthropogenic and Natural Hazards".

\section{REFERENCES}

[1] Drdácký, M., Slížková, Z. \& Valach, J., Příspěvek technických věd k záchraně a restaurování památek, ÚTAM AV ČR: Prague, p. 243, 2015.

[2] Baglioni, P., Giorgi, R. \& Dei, L., Soft condensed matter for the conservation of cultural heritage. C. R. Chimie, 12, pp. 61-69, 2012.

[3] Chelazzi, D. et al., Hydroxide nanoparticles for cultural heritage: Consolidation and protection of wall paintings and carbonate materials. Journal of Colloid Interface Science, 392, pp. 42-49, 2013. DOI: 10.1016/j.jcis.2012.09.069.

[4] Dei, L. \& Salvadori, B., Nanotechnology in cultural heritage conservation: Nanometric slaked lime saves architectonic and artistic surfaces from decay. Journal of Cultural Heritage, 7, pp. 110-115, 2006.

[5] Baglioni, P., Carretti, E. \& Chelazzi, D., Nanomaterials in art conservation. Nature Nanotechnology, 38, pp. 287-290, 2015. DOI: 10.1038/nnano.2015.38. 
[6] Slížková, Z. \& Frankeová, D., Consolidation of porous limestone with nanolime: laboratory study. Proceedings of the 12th International Congress on the Deterioration and Conservation of Stone, 2012.

[7] Maryniak-Piaszczynski, E., Wolf, V. \& Ghaffari, E., The combination of calcium hydroxide-sol and silicic acid ester as new method for structural consolidation of objects built of tuff, lime marl, trachyte: latest findings. Proceedings of the 12th International Congress on the Deterioration and Conservation of Stone, 2012.

[8] Kroftová, K., Kubát, J. \& Škoda, D., Possibilities of consolidation of historical materials with selected nanodispersions: Results of experimental research of the strength degree on reference formulas. NaNs: Moderní materiály a technologie ve stavebnictví, 2018.

[9] Kroftová, K., Kuřitka, I., Škoda, D., Šmidtová, M. \& Masař, M., Synthesis of nanolime suspension and their potential use in cultural heritage preservation. EASEC 15 - The Fifteenth East Asia - Pacific Conference on Structural Engineering and Construction, 2017.

[10] Leyva-Porras, A. et al., Low-temperature synthesis and characterization of anatase TiO2 nanoparticles by an acid assisted sol-gel method. Journal of Alloys and Compounds, 647, pp. 627-636, 2015.

[11] Neubergová, S., Analýza vlivu vybraných degradačních činitelů na fyzikálně mechanické vlastnosti prrírodního kamene, DDP, Praha: České vysoké učení technické v Praze, 2015.

[12] Witzany, J. et al., The effect of pore distribution in historic masonry on the grouting method and the grouting mix selection. The Civil Engineering Journal, 3, pp. 307329, 2018.

[13] Papayianni, I. \& Pachta, V., Experimental study on the performance of lime-based grouts used in consolidating historic masonries. Materials and Structures, 48, pp. 2111-2121, 2015. DOI: 10.1617/s11527-014-0296-5.

[14] Schönhofer, K., Calciumhydroxid-Sol Ein Festigungsmittel für Historische Putze. Diploma thesis, Fachhochschule Cologne, Germany, p. 111, 2006. 